\title{
Evaluation of Castor Bark Powder as a Corrosion Inhibitor for Carbon Steel in Acidic Media
}

\author{
André de Mendonça Santos ${ }^{a *}$, Thassia Felix de Almeida ${ }^{a}$, Fernando Cotting ${ }^{b}$, Idalina Vieira Aoki ${ }^{b}$, \\ Hercílio Gomes de Melo ${ }^{c}$, Vera Rosa Capelossi ${ }^{a}$ \\ ${ }^{a}$ Universidade Estadual de Santa Cruz, Campus Soane Nazaré de Andrade (Salobrinho), Km 16 - \\ BR-415, CEP 45662-900, Ilhéus, BA, Brazil \\ ${ }^{b}$ Departamento de Engenharia Química, Escola Politécnica da Universidade de São Paulo, A. \\ Prof. Luciano Gualberto, trav. 3, $n^{\circ}$ 380, CEP05508-010, São Paulo, SP, Brazil \\ 'Departamento de Engenharia Metalúrgica e de Materiais, Escola Politécnica da Universidade de \\ São Paulo, Av. Prof. Mello Moraes, $n^{\circ}$ 2463, CEP 05508-030, São Paulo, SP, Brazil
}

Received: December 10, 2016; Revised: September 01, 2017; Accepted: September 17, 2017

\begin{abstract}
The inhibition effect of castor bark powder obtained from Ricinus communis on AISI 1020 carbon steel in acidic media $\left(\mathrm{HCl} 0.5 \mathrm{~mol}^{-\mathrm{L}^{-1}}\right)$ has been studied by electrochemical impedance spectroscopy (EIS), polarization curves, scanning vibrating electrode technique (SVET) and weight loss measurements. Fourier transform infrared spectroscopy (FTIR) and scanning electron microscopy (SEM) were employed as characterization techniques. The EIS and gravimetric results showed that the inhibitory efficiency increases with inhibitor concentration achieving $83 \%$. Polarization curves indicated that the castor bark powder acts as mixed inhibitor. The adsorption of the powder components on the metal surface follows the Langmuir isotherm. The FTIR analyses indicate the presence of $\mathrm{C}, \mathrm{N}$ and $\mathrm{O}$ heteroatoms, incorporated in functional groups mainly related to the presence of carboxylic acids as ricinoleic acid, which could be responsible for the inhibitory properties of the powder. SEM analyses showed that the corrosion process was retarded in the presence of inhibitor in the electrolyte, which was confirmed by SVET measurements. Therefore, the results indicate that castor bark powder has potential to be a corrosion inhibitor for carbon steel in acidic media.
\end{abstract}

Keywords: Carbon Steel, EIS, Ricinus communis, SVET, Green inhibitors

\section{Introduction}

Metals and alloys are widely used in industrial applications such as automobiles, petroleum refining, architecture and others. Among them, carbon steel has an important place due to its low cost, good mechanical properties and workability, thermal conductivity, etc. However, this material has low corrosion resistance in acidic media, which can lead to economic losses. Industrial processes as acid cleaning, acid pickling and oil acidification typically use aggressive species, such as hydrochloric acid, which severely attacks carbon steel, being necessary the use of corrosion inhibitors to protect it ${ }^{1,2}$.

Corrosion inhibitors are substances which when added in small quantities to solutions can significantly decrease the metal corrosion rate. One of the proposed inhibitory mechanisms consists in the adsorption of the molecules to the metal surface, creating a barrier between the metal and the electrolyte, blocking active sites and reducing the metal dissolution and/or reduction reactions ${ }^{3}$. Many of these inhibitors are organic molecules containing nitrogen, oxygen, sulphur, and phosphorous heteroatoms in their structures, which can adsorb into active sites of the metal surface through conjugated bonds ${ }^{4}$.

Several conditions must be considered in the choice of an inhibitor, such as, its cost, availability and toxicological effects to humans and to the environment ${ }^{5}$. Many synthetic inhibitors are known for their toxic properties and high costs. Because of this, researchers have been focused in investigating the inhibitory properties of easily available and low cost natural products that, in addition, are not harmful to health and to the environment, which are generally denominated green inhibitors ${ }^{6}$. In the literature, several studies are available on the efficiency of leaves or peel extracts as corrosion inhibitors for carbon steel in acidic solutions (generally electrolyte prepared using $37 \% \mathrm{~m} / \mathrm{v} \mathrm{HCl}$ ), like aqueous extracts of mango and orange peel $^{2}$, and alcoholic extracts of Astemisia Mesatlantica oil ${ }^{7}$, Roselle $^{8}$, Eruca sativa ${ }^{9}$, Saccocalyx satureioides ${ }^{10}$, Argemone mexicana $^{6}$, Chrysophyllum albidum ${ }^{11}$, Agavoideae ${ }^{12}$, Tiliacora accuminata $^{13}$, Pimenta dioica ${ }^{14}$, Ilex paraguariensi ${ }^{15}$, Aniba rosa eodora ${ }^{16}$, Ruta chalepensis ${ }^{17}$. 
Castor (Ricinus communis) is a fruit used to produce castor oil. The seeds, after being separated from the bark, are submitted to a production process, which involves their pressing to obtain the castor oil. The oil has a wide range of applications, especially in food industry, lubricant, cosmetic ingredient and as source for renewable fuel. The northeast of Brazil is a tropical area that has good conditions for castor cultivation, boosting its production in this region. The state of Bahia is the largest castor producer in Brazil being the castor oil industry an important source of jobs and incomes for the state ${ }^{18}$. However, the oil production generates a large amount of by-products, which recycling is a major challenge for the castor oil industry ${ }^{19}$. Several investigations ${ }^{20-22}$ have already demonstrated that derivatives of the castor oil productive cycle can effectively act as corrosion inhibitor for steel in acidic media. For instance, extract of Ricinus communis leaves was investigated as corrosion inhibitor for mild steel and achieved $84 \%$ efficiency ${ }^{20}$; three isolated compounds of Ricinus communis were tested as corrosion inhibitors and a maximum efficiency of $87 \%$ was achieved for ricinine $^{21}$. Efficiency of $87 \%$ against corrosion of mild steel in hydrochloric acid media can be achieved using castor oil ${ }^{22}$.

One of the by-products generated during castor oil production is the bark, and the aim of the present work is to investigate the potentiality of castor bark (Ricinnus communis) powder as corrosion inhibitor for AISI 1020 carbon steel in acidic media ( $\mathrm{HCl} 0.5$ mol. $\mathrm{L}^{-1}$ ) using electrochemical techniques and weight loss measurements.

\section{Experimental}

The AISI 1020 carbon steel (CS) samples were cut into (20 $\mathrm{x} 20 \mathrm{x} 8$ ) mm dimensions, which, previously to testing, were progressively ground using different emery paper $(80,120$, $320,400,600$ and 1200 grit) and then washed with distilled water, ethanol and acetone and dried under a hot air stream.

The castor was granted by farmers of the Camacan city (Bahia, BR). Initially, the bark was extracted from the seeds employing a knife at the Materials and Environment Laboratory (LAMMA) of UESC (State University of Santa Cruz - BA), where some of the experiments were performed. Then, it was washed in distilled water to remove unwanted impurities and dried in an oven at $70^{\circ} \mathrm{C}$ for $24 \mathrm{~h}$. To reduce the particles size to a powder, the dried material was milled to above 170 mesh. Corrosion and electrochemical tests were carried out using five different amounts of castor bark powder added to the test electrolyte: 0.44 g.L - $^{-1}, 0.77$ g.L. ${ }^{-1}, 1.11$ g.L $L^{-1}$, 1.44 g.L. $\mathrm{L}^{-1}$ and 1.77 g.L $\mathrm{L}^{-1}$. These amounts were previously used at LAMMA in studies about natural inhibitors as cocoa and garlic barks ${ }^{23}$, and were maintained for comparison purposes.

Fourier transform infrared spectroscopy (FTIR) analyses were carried out for chemical characterization, using a Thermo Scientific ${ }^{\mathrm{TM}}$ Nicolet $^{\mathrm{TM}}$ is ${ }^{\mathrm{TM}} \mathbf{1 0}$ FT-IR Spectrometer.
The spectrum was obtained at room temperature in the range of $400-4000 \mathrm{~cm}^{-1}$ at a resolution of $4 \mathrm{~cm}^{-1}$. The samples were prepared for the analysis using $\mathrm{KBr}$ pellets.

The electrochemical experiments were carried out in triplicate with a potentiostat/galvanostat Metrohm Autolab, model PGSTAT302N, with impedance module. A conventional three-electrode cylindrical glass cell was used with the AISI 1020 carbon steel sample as working electrode ( $1 \mathrm{~cm}^{2}$ of exposed surface area), $\mathrm{Ag}|\mathrm{AgCl}| \mathrm{KClsat}$ as reference electrode and a titanium wire coated with rhodium as auxiliary electrode. The electrolyte was a 0.5 mol.L ${ }^{-1} \mathrm{HCl}$ (Anidrol) solution without or with different amounts of the castor bark powder. The experiments were controlled by the software NOVA 1.11 and the data were treated with software Microcal ${ }^{\circledR}$ Origin $^{\circledR}$ 8.0.

Electrochemical impedance spectroscopy (EIS) diagrams were acquired at the open circuit potential (OCP) after $90 \mathrm{~min}$ of stabilization, from $10 \mathrm{kHz}$ to $10 \mathrm{mHz}$, with 10 points per frequency decade using a potential perturbation amplitude of $10 \mathrm{mV}$. For quantitative analyses, the EIS data were fitted with ZView2 software.

Potentiodynamic polarization curves were obtained subsequently to the EIS measurements. Anodic sweeps were performed from $-30 \mathrm{mV} v s$ OCP to $+250 \mathrm{mV} v s$ OCP, whereas cathodic curves from $+30 \mathrm{mV} v s$ OCP to $-250 \mathrm{mV}$ vs OCP at a scan rate of $0.5 \mathrm{mV} \mathrm{s}^{-1}$. To check reproducibility of results, different samples of working electrode were employed to acquire each branch.

Weight loss measurements were carried out in triplicate according to AISI-G1 ${ }^{24}$ standard using rectangular samples $(20 \times 20 \times 8) \mathrm{mm}$. The immersion time was $120 \mathrm{~min}$, in the $0.5 \mathrm{~mol} \mathrm{~L}^{-1} \mathrm{HCl}$ acid pickling solution without and with different amounts of castor bark powder. With the aim of removing corrosion products from samples surface, they were gently scrubbed with toothbrush and then washed with distilled water, alcohol, acetone and dried under a hot air stream after the immersion test. From the results, corrosion rates and inhibiting efficiencies were determined.

The scanning vibrating electrode technique (SVET) was performed using the Applicable Electronics equipment controlled by ASET-Sciencewares software. The data treatment was carried out using the software QuikGrid in version 5.4. A microelectrode of platinum/iridium from MicroProbes with a platinum deposit of about $10 \mu \mathrm{m}$ at its tip was used as vibrating electrode and two auxiliary platinum electrodes were used. The distance between the sample and the vibrating probe was $150 \mu \mathrm{m}$. The electrolyte used was $\mathrm{HCl} 1.10^{-3}$ mol. $\mathrm{L}^{-1}$, which is less aggressive than the other used in this work, because SVET is a localized electrochemical technique and the appearance of bubbles during the experiment affects the measurements, so a less aggressive medium is always used to permit sensing the very beginning of the corrosion process. 
The morphologies of the samples surfaces after 120 min immersion in the test electrolyte in the absence and in the presence of the castor bark powder were acquired by scanning electron microscopy (SEM). SEM analyses were obtained by Quanta 250F.

\section{Results and Discussion}

\subsection{Chemical characterization}

\subsubsection{Fourier transform infrared spectroscopy (FTIR)}

Figure 1 shows the FTIR spectrum of the castor bark powder. The large peak centered at $3421 \mathrm{~cm}^{-1}$ can be attributed to $\mathrm{OH}$ or/and $\mathrm{NH}$ from water or amines ${ }^{25,26}$. Absorption peak at $2923 \mathrm{~cm}^{-1}$ can be assigned to $\mathrm{C}-\mathrm{H}$ and its low intensity indicates that only short chain compounds are detected ${ }^{27,28}$. The band at $1653 \mathrm{~cm}^{-1}$ can be assigned to carbonyl group $\mathrm{CN}$ or $\mathrm{C}=\mathrm{O}$ from carboxylates, as unsaturated carboxylic acids (ricinoleic acid) are present in the castor oil composition ${ }^{6,26}$. The absorption band at $1457 \mathrm{~cm}^{-1}$ corresponds to $\mathrm{CH}_{3}{ }^{6}$. Finally, the functional group $\mathrm{C}-\mathrm{O}$ can be identified in the band at $1053 \mathrm{~cm}^{-11,26}$.

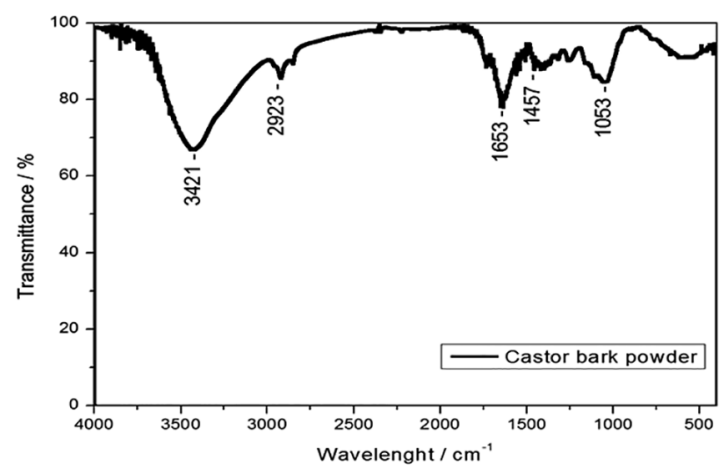

Figure 1. FTIR spectra of castor bark powder.

The FTIR analyses indicates the presence of $\mathrm{C}, \mathrm{N}$ and $\mathrm{O}$ heteroatoms incorporated in different functional groups, which were also identified in compounds of Ricinus communis ${ }^{21}$. These heteroatoms are generally found in green inhibitors, whose inhibitory properties are commonly attributed to them ${ }^{6}$. These substances are adsorbed on carbon steel surface forming $\mathrm{Fe}^{2+}$-Green Inhibitor complexes, which could be responsible for retarding the corrosion process ${ }^{29}$.

\section{Gravimetric test}

The inhibition efficiency and corrosion rate $\left(\mathrm{C}_{\mathrm{R}}\right)$ calculated for AISI 1020 carbon steel from the whole set of weight loss experiments are presented in Table 1 . The values of $C_{R}$ were calculated from Equation 1, where $\Delta W$ is the average weight loss in grams, $A$ is the total exposed area (average $8.3 \mathrm{~cm}^{2}$ ), and $t$ is the immersion time in hours?

$$
C_{R}=\frac{\Delta W}{A . t}
$$

The inhibition efficiency $\left(\eta_{\mathrm{wL}}\right)$ was calculated from Equation 2, where $C_{R o}$ and $C_{R i}$ are the corrosion rates of carbon steel specimens in the absence and presence of inhibitor, respectively ${ }^{7}$.

$$
\eta_{W L}=\left(1-\frac{C_{R i}}{C_{R o}}\right) x 100
$$

The corrosion current density $\left(i_{\text {corr }}\right)$ was calculated from Equation 3, where 96500 is the Faraday constant (C) and $E_{\text {qmetal }}$ is the equivalent gram for the carbon steel electrode, which was assumed to be $27.93 \mathrm{~g}$, corresponding to pure iron.

$$
i_{\text {corr }}=C_{R} \frac{96500}{E_{\text {qmetal }}}
$$

Table 1 shows that $C_{R}$ and $i_{\text {corr }}$ decrease with increasing inhibitor concentration. This indicates that the addition of castor bark powder to the solution, even in small amounts, hinders the electron transfer between the metal and the electrolyte. It is proposed that the inhibitor may block active sites at the metal surface by adsorption, decreasing the exposed area and reducing the corrosion rate of the material ${ }^{6}$.

The results displayed in Table 1 show that the inhibition efficiency of castor bark powder against AISI 1020 carbon steel corrosion increases up to $83 \%$ when 1.77 g.L.- was added to the solution. Several scientists in their studies reported similar results for green inhibitors ${ }^{4,10,30-33}$. The maximum values achieved are also compatible with those found for other castor oil compounds ${ }^{20-22}$. In addition, from 0.77 g.L.- ${ }^{-1}$, the efficiency is higher than $70 \%$, which is indicated in classic literature as an acceptable value for an efficient inhibitor ${ }^{34}$. Table 1 also shows that the inhibition efficiency determined when 1.44 g.L.- of castor bark powder was added to the aggressive electrolyte ( $80 \%$ ) is very close to that found for $1.77 \mathrm{~g} . \mathrm{L}^{-1}$ of inhibitor. This indicates that probably a critical inhibitor concentration was reached and that further addition of the powder to the electrolyte would have only negligible effect on hindering the corrosion process.

\subsection{Adsorption Isotherm}

Fitting the surface coverage for different inhibitor concentrations with adsorption isotherms can be used to provide information about the interaction between inhibitormetal- interfaces ${ }^{4}$. In aqueous solutions, the metal surface is covered by adsorbed water dipoles, which may be displaced and replaced by the inhibitors molecules ${ }^{16}$. The simplest of the isotherms, the Langmuir one, is given in Equation $4^{35}$ and assumes that the adsorbed inhibitor molecules occupy only one site at the metal surface and that there are no interactions between neighboring adsorbed species. In Eq.4, $C$ is the inhibitor concentration, $K$ stands for the adsorption 
Table 1. Corrosion rate, corrosion current density, coverage degree and inhibitory efficiency calculated from gravimetric experiments for AISI 1020 carbon steel, after immersion during $120 \mathrm{~min}$ in $0.5 \mathrm{~mol} . \mathrm{L}^{-1} \mathrm{HCl}$ solution, in the absence and in the presence of different amounts of castor bark powder.

\begin{tabular}{ccccc}
\hline $\begin{array}{c}\text { Concentration } \\
\text { (g.L-L })\end{array}$ & $\begin{array}{c}\mathbf{C}_{\mathbf{R}} \\
\left(\mathbf{g} . \mathbf{h}^{-1} \cdot \mathbf{c m}^{-2}\right)\end{array}$ & $\begin{array}{c}\mathbf{i}_{\text {corr }} \\
\left(\mathbf{A} . \mathbf{c m}^{-2}\right)\end{array}$ & $\boldsymbol{\eta}_{\mathrm{wL}}$ & $\boldsymbol{\theta}$ \\
\hline $\mathbf{B l a n k}$ & $1.96 \times 10^{-4}$ & 0.68 & & \\
$\mathbf{0 . 4 4}$ & $0.69 \times 10^{-4}$ & 0.24 & $65 \%$ & 0.65 \\
$\mathbf{0 . 7 7}$ & $0.59 \times 10^{-4}$ & 0.20 & $70 \%$ & 0.70 \\
$\mathbf{1 . 1 1}$ & $0.51 \times 10^{-4}$ & 0.18 & $74 \%$ & 0.74 \\
$\mathbf{1 . 4 4}$ & $0.39 \times 10^{-4}$ & 0.13 & $80 \%$ & 0.80 \\
$\mathbf{1 . 7 7}$ & $0.33 \times 10^{-4}$ & 0.12 & $83 \%$ & 0.83 \\
\hline
\end{tabular}

equilibrium constant and $\theta$ is the fractional coverage degree $\left[\eta_{\mathrm{WL}}(\%) / 100\right]^{36}$ :

$$
\frac{C}{\theta}=\left(\frac{1}{K}\right)+C
$$

Figure 2 presents the plot of $(\mathrm{C} / \theta)$ against $\mathrm{C}$, according to the data presented in Table 1. A linear plot was obtained, with a correlation coefficient $\left(\mathrm{R}^{2}\right)$ higher than 0.99 , suggesting that the inhibitor adsorption follows the Langmuir isotherm. The angular coefficient close to 1.0 further confirms the obedience to this isotherm model. This adsorption behaviour is in accordance with other previously reported for green inhibitors on carbon steel surface in different acidic media ${ }^{2,8,37}$.

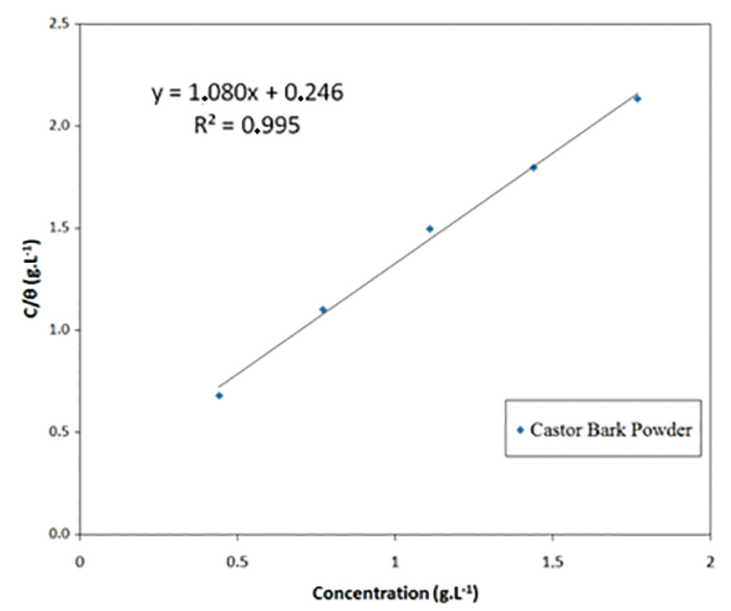

Figure 2. Langmuir adsorption plots for AISI 1020 carbon steel containing different amounts of castor bark powder in $\mathrm{HCl} 0.5$ mol. $\mathrm{L}^{-1}$.

The Gibbs standard free energy of adsorption $\left(\Delta \mathrm{G}^{\circ}{ }_{\text {ads }}\right)$ of $-16.92 \mathrm{~kJ} \mathrm{~mol}^{-1}$ was calculated using Equation 5:

$$
\Delta G_{a d s}^{\circ}=-R T \ln \left(C_{H_{2} O} K\right)
$$

where $R$ is the universal gas constant $\left(8.3147 \mathrm{~J} \cdot \mathrm{mol}^{-1} \cdot \mathrm{K}^{-1}\right)$, $T$ is the absolute temperature ( $298 \mathrm{~K}), C_{\mathrm{H}_{2} \mathrm{O}}=1000 \mathrm{~g} . \mathrm{L}^{-1}$ is the water concentration and $K$ is the adsorption equilibrium constant obtained from data fitting with equation 4. It should be noted that the unit of $C_{\mathrm{H}_{2} \mathrm{O}}$ lies in that of $K^{10,29}$.

A negative $\Delta G_{a d s}^{\circ}$ suggests that the adsorption of the inhibitor to the substrate surface is spontaneous. In addition, it indicates physical interaction between the molecules and metal surface, which tends to form an adsorption layers with

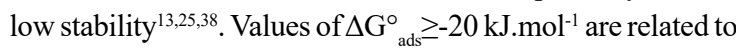
weak electrostatic interaction between the charged molecules and the charged metal surface (physisorption) that form a nonstable and not long lasting and protective adsorbed layers. On the other hand, those around $-40 \mathrm{~kJ} \cdot \mathrm{mol}^{-1}$ are consistent with charge sharing or transfer from the inhibitor molecules to the metal surface to form a coordinate bond (chemisorption) $)^{8,29,38}$.

\subsection{Effect of immersion time on the corrosion inhibition efficiency}

The influence of immersion time on the corrosion inhibition efficiency was investigated by the gravimetric method. Table 2 presents the results of the corrosion rates and corrosion current densities, calculated according to Eq. 1 and 3, respectively,

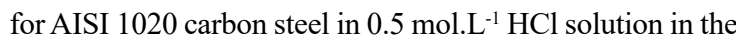
presence of $1.77{\mathrm{~g} . \mathrm{L}^{-1}}^{-1}$ of castor bark powder after different immersion times. The results show that $C_{R}$ and $i_{\text {corr }}$ increase with immersion time, suggesting deterioration of the inhibitory properties and indicating that electrons exchange between the metal and $\mathrm{H}^{+}$becomes easier, enhancing the corrosion process. The comparison of $i_{\text {corr }}$ values between Table 1 and 2 confirms this analysis, where it can be noted that after $24 \mathrm{~h}$ of exposure, the $\mathrm{i}_{\text {corr }}$ value for solution with $1.77 \mathrm{~g} . \mathrm{L}^{-1}$ of castor bark powder is higher than $i_{\text {corr }}$ value for the blank sample after $2 \mathrm{~h}$ of exposure, which confirms that the inhibitor lost its corrosion protection due to immersion time. These results are in accordance with the $\Delta \mathrm{G}^{\circ}$ ads values previously determined and confirm weak interactions between the inhibiting molecules and the metal surface, indicating that the castor bark powder may be used only for applications where long immersion periods are not required, like in pickling processes. Similar behaviour was reported for aqueous extract of Argemone mexicana roots ${ }^{6}$ and for aqueous coffee ground extracts ${ }^{39}$ for carbon steel in 1 mol. $\mathrm{L}^{-1} \mathrm{HCl}$. 
Table 2. Corrosion rates and corrosion current densities calculated from gravimetric experiments for AISI 1020 carbon steel immersed for different times in 0.5 mol. $\mathrm{L}^{-1} \mathrm{HCl}$ solution with $1.77 \mathrm{~g} . \mathrm{L}^{-1}$ of castor bark powder.

\begin{tabular}{ccc}
\hline $\begin{array}{c}\text { Immersion time } \\
(\mathbf{h})\end{array}$ & $\begin{array}{c}\mathbf{C}_{\mathbf{R}} \\
\left(\mathbf{g . h} \mathbf{h}^{-\mathbf{.}} \mathbf{c m}^{-\mathbf{2}}\right)\end{array}$ & $\begin{array}{c}\mathbf{i}_{\text {corr }} \\
(\mathbf{A . c m})\end{array}$ \\
\hline $\mathbf{2} \mathbf{~ h}$ & $0.33 \times 10^{-4}$ & 0.12 \\
$\mathbf{6 ~ h}$ & $1.05 \times 10^{-4}$ & 0.36 \\
$\mathbf{1 2} \mathbf{~ h}$ & $1.46 \times 10^{-4}$ & 0.50 \\
$\mathbf{2 4} \mathbf{~ h}$ & $2.52 \times 10^{-4}$ & 0.87 \\
\hline
\end{tabular}

\section{Electrochemical Techniques}

\subsection{Electrochemical impedance spectroscopy (EIS)}

The EIS diagrams obtained at the OCP after $90 \mathrm{~min}$ immersion of the AISI 1020 carbon steel in the test electrolyte in the presence of different amounts of castor bark powder are presented in Figure 3. Initially, the results show that the addition of the powder to the test solution does not change the shape either of the Nyquist (Fig. 3(a)) or of the phase angle $\mathrm{x} \log \mathrm{f}$ (Fig. 3(b)) diagrams indicating that there is no modification of the corrosion mechanism ${ }^{16,32}$. In addition, for all experiments, Nyquist plots (Fig. 3(a)) are composed by a single depressed capacitive loop, which diameter and capacitive behavior (Fig. 3(b)) increases with increasing amount of powder added to the electrolyte, evidencing enhanced corrosion resistance. This confirms that castor bark powder inhibits the corrosion of the substrate, which must be a consequence of increased adsorption of molecules with inhibitory properties to the metallic surface hindering the electrochemical process. This hypothesis is in accordance with the adsorption isotherm previously determined, and, is a behaviour already verified for other green inhibitors ${ }^{40,41}$.

For a quantitative evaluation of the effects of castor bark powder addition in the corrosion resistance of the CS AISI 1020, impedance diagrams were fitted using the electrical equivalent circuit (EEC) presented in Figure 4. The model is composed by a single time constant and has been commonly used to fit impedance diagrams of CS in acidic solutions, without or with inhibitor addition ${ }^{17,32,42-44}$. In the circuit, $\mathrm{R}_{\mathrm{S}}$ is the solution resistance, $\mathrm{R}_{\mathrm{ct}}$ the charge transfer resistance and $\mathrm{CPE}_{\mathrm{dl}}$ is a constant phase element (CPE) accounting for the double layer capacity. In EEC fitting of EIS diagrams, capacitances are frequently replaced by CPE to take into account frequency dispersion in the diagrams (depressed loops). The impedance of a CPE can be calculated by means of Equation $6^{45}$, at which $\mathrm{Q}$ is the $\mathrm{CPE}$ constant and $\alpha$ is the dispersion factor, other variables having their usual meaning. For $\alpha=1, \mathrm{Q}$ is a pure capacitor and the electrode behaves ideally, $\alpha=0.5$ is obtained when a diffusion-controlled process occurs ${ }^{46,47}$ or when the electrode is porous ${ }^{48,49}$, whereas for $0.5<\mathrm{n}<1.0$ the deviation from the ideal capacitive behaviour is attributed to heterogeneities in the electrode surface or to non-homogeneous current distribution on the electrode surface ${ }^{50,51}$. Table 3 shows the results of the EEC fitting procedure.

$$
Z_{C P E}=\frac{1}{Q(j \omega)^{\alpha}}
$$

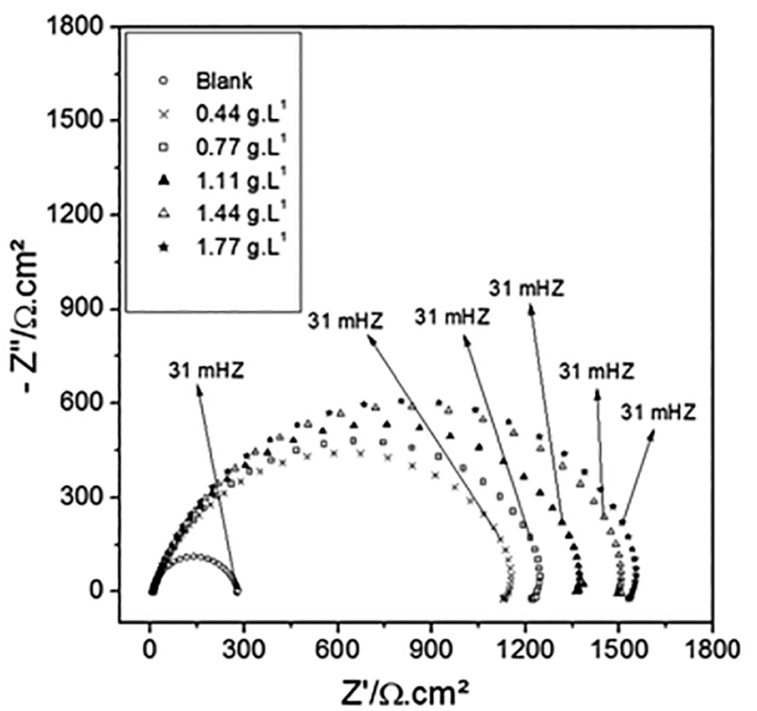

(a)

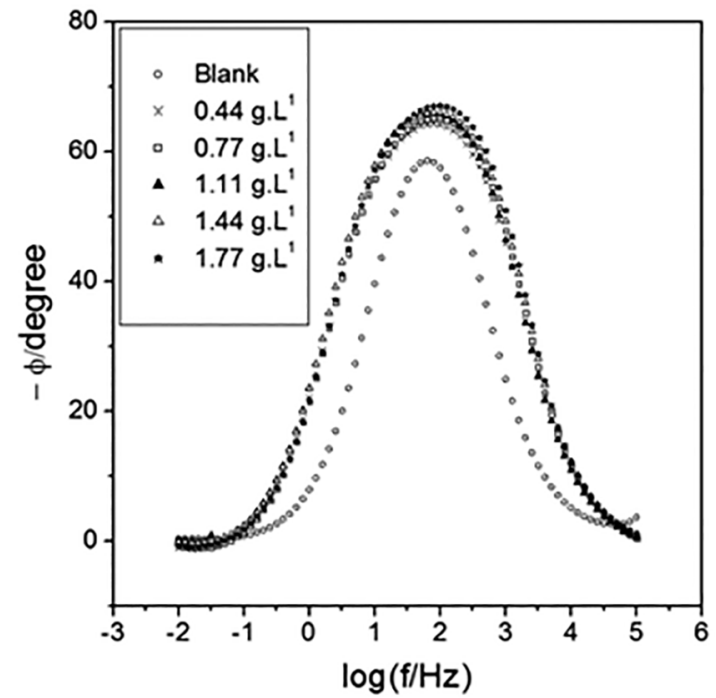

(b)

Figure 3. EIS diagrams obtained for AISI 1020 carbon steel after $120 \mathrm{~min}$ of immersion in $0.5 \mathrm{~mol} . \mathrm{L}^{-1} \mathrm{HCl}$ in absence and presence of different amounts of castor bark powder: (a) Nyquist and (b) phase angle $\mathrm{x} \log \mathrm{f}$ plots. 


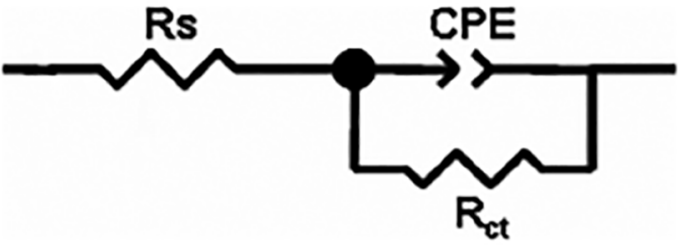

Figure 4. Equivalent circuit used to fit the EIS data.

For a one time constant process, $\mathrm{R}_{\mathrm{CT}}$ is directly proportional to the corrosion resistance. Data in Table 3 clearly show that $\mathrm{R}_{\mathrm{CT}}$ increases when increased amounts of castor bark powder are added to the test solution, confirming the results of the weight loss experiments. The inhibitory efficiency against corrosion (IE\%) was calculated using Equation 7, where $\mathrm{R}_{\mathrm{CT}(0)}$ and $\mathrm{R}_{\mathrm{CT}(\mathrm{w})}$ are the charge transfer resistance in the absence and in the presence of the inhibitive compound, respectively. The values depicted in Table 3 show the same trend as those calculated from the weight loss measurements (Table 2) but with slightly higher values. This discrepancy can be likely ascribed to the longer immersion time for the weight loss experiments (120 min) when compared to the EIS ones (90 min). As shown in the investigation of the effect of immersion time on the corrosion inhibition efficiency, this parameter decreases with increasing immersion time. Therefore, the longer immersion period taken for the weight loss determination would explain this difference. Interestingly, the discrepancies between the two methodologies diminishes for increasing amounts of castor bark powder added to the aggressive medium, indicating that higher concentration of molecules with inhibitory properties (proportional to the powder amount) is able to keep the inhibitory properties for a longer period.

$$
I E \%=\frac{R_{C T(w)}-R_{C T(0)}}{R_{C T(w)}} \times 100
$$

As already stated, the classic literature reports that the inhibitory efficiency against corrosion must be higher than $70 \%$ for an inhibitor to be classified as efficient ${ }^{34}$. Table 3 shows that the inhibitor efficiency calculated from the EIS data fitting achieves more than $70 \%$, which ever the amount of bark powder added to the test solution. These values are the same order of magnitude to those found in the literature for other natural inhibitors, like as Aniba rosaeodora extract $(95 \%)^{16}$, Loquat leaf extract $(76 \%)^{27}$, coffee ground extracts $(93 \%)^{39}$, and others castor oil compounds, such as Ricinus communis ethanolic extracts $(84 \%)^{20}$, and castor oil $(87 \%)^{22}$. Therefore, the present methodology suggests that the use of castor bark powder as corrosion inhibitor is feasible. In addition, the inhibition efficiencies determined with this methodology were equal when 1.44 g.L. ${ }^{-1}$ or 1.77 g.L. $L^{-1}$ of the powder was added to the electrolyte. This is in quite good agreement with the results determined from the weight loss measurements (Table 1) and further indicates that a critical inhibitor concentration was reached. The data of Table 3 also points that upon increasing the amount of the inhibitor above the critical concentration the inhibiting efficiency is not decreased, as sometimes found for other inhibitors ${ }^{19}$.

The values reported in Table 3 for the dispersion coefficient $(\alpha)$ show that it lies between 0.8 and 0.9 , approaching a capacitive behaviour, and it slightly decreases when the powder is added to the electrolyte, remaining almost unchanged whatever the castor bark powder amount. As largely discussed in the literature, interpretation about CPE and their exponents are controversial ${ }^{52}$ and methodologies have been developed to determine an effective capacity value $\left(\mathrm{C}_{\mathrm{eff}}\right)^{53}$ which can be used to disclose the double layer capacity according to Brug formula ${ }^{54}$. However, considering that there are not many differences between the $\alpha$ values of the experiments, a qualitative comparison can be performed for the CPE variation with the castor bark powder amount, allowing associating it with the properties of the interface. According to Helmholtz equation, the double layer capacity can be calculated with Equation 8, where $d$ is the thickness of the double layer, $\varepsilon$ is the dielectric constant of the medium and $\varepsilon_{\mathrm{o}}$ is the vacuum permittivity, which is a constant ${ }^{55}$. Therefore, modifications of the parameters $\varepsilon$ and $d$ can produce changes in $\mathrm{C}_{\mathrm{dl}}$, which in Table 3 is proportional to $\mathrm{CPE}_{\mathrm{dl}}$. Water molecules and/or chloride ions can be displaced from the electrode surface by the inhibitors molecules ${ }^{44}$, thus diminishing the dielectric constant of the double layer. In addition, the bigger size of the organic molecules with

Table 3. Parameters from the fitting of EIS diagrams with the equivalent circuit of Figure 4 for corrosion of AISI 1020 carbon steel in $0.5 \mathrm{~mol} . \mathrm{L}^{-1} \mathrm{HCl}$ in the absence and presence of different amounts of castor bark powder.

\begin{tabular}{|c|c|c|c|c|c|}
\hline $\begin{array}{c}\text { Concentration } \\
\left(\text { g. } \mathrm{L}^{-1}\right)\end{array}$ & $\begin{array}{c}\text { Rs } \\
\left(\Omega \cdot \mathbf{c m}^{2}\right)\end{array}$ & $\begin{array}{c}\text { Ret } \\
\left(\Omega \cdot \mathbf{c m}^{2}\right)\end{array}$ & $\begin{array}{c}\mathrm{CPE}_{\mathrm{dl}} \\
\mu \mathrm{Fcm}^{-2} \mathbf{s}^{(\alpha-1)}\end{array}$ & $\alpha$ & $\begin{array}{c}\text { Inhibition } \\
\text { Efficiency } \\
(\%)\end{array}$ \\
\hline Blank & 6.25 & 272 & $15.6 \mathrm{E}-05$ & 0.88 & \\
\hline 0.44 & 6.15 & 1195 & $9.2 \mathrm{E}-05$ & 0.81 & $77 \%$ \\
\hline 0.77 & 6.15 & 1286 & $8.0 \mathrm{E}-05$ & 0.81 & $79 \%$ \\
\hline 1.11 & 6.16 & 1415 & $8,1 \mathrm{E}-05$ & 0.82 & $81 \%$ \\
\hline 1.44 & 6.14 & 1561 & $7,3 \mathrm{E}-05$ & 0.82 & $83 \%$ \\
\hline 1.77 & 6.19 & 1599 & $6,3 \mathrm{E}-05$ & 0.83 & $83 \%$ \\
\hline
\end{tabular}


inhibitory activity increases the thickness of the double layer ${ }^{42,56}$. These two features contribute to diminish $\mathrm{C}_{\mathrm{dl}}$, which is in accordance both with the decreasing of $\mathrm{CPE}_{\mathrm{dl}}$ values for increasing amounts of castor bark powder (Table 3) and with the adsorption of inhibiting molecules to the electrode surface, previously indicated by the adsorption isotherm.

$$
C_{d l}=\frac{\varepsilon \varepsilon_{o}}{d}
$$

\subsection{Potentiodynamic polarization curves}

Potentiodynamic polarization curves for AISI $1020 \mathrm{CS}$ in the absence and presence of different amounts of castor bark powder in $0.5 \mathrm{~mol} . \mathrm{L}^{-1} \mathrm{HCl}$ solution are show in Figure 5. They were obtained after 120 min of immersion, after OCP monitoring and EIS measurements. Figure 5 reveals that both anodic and cathodic polarization curves are shifted towards lower current densities whenever castor bark powder was added to the electrolyte. The current densities were reduced by almost two orders of magnitude for all concentrations, confirming the presence of substances with inhibitory properties in the powder composition. It can be noted that the polarization curves are shifted towards more positive potentials, revealing that castor bark powder acts as mixed inhibitor with slight anodic predominance. Similar behaviours were found in the literature for CS in acidic solutions in the presence of green inhibitors ${ }^{2,9,16,57}$.

The anodic curves (Fig. 5(a)) indicate that metal oxidation is controlled by activation, since they feature a long linear stretch (Tafel behaviour), whereas the cathodic process is clearly $\mathrm{H}^{+}$reduction. In addition, the shapes of both branches do not change with the addition of castor bark powder, further indicating that the corrosion mechanism does not change and that the inhibiting molecules act by blocking the reaction $\operatorname{sites}^{28}$, which is in agreement with the EIS results.

\subsection{Scanning vibrating electrode technique (SVET)}

The SVET measurements were carried out by adding 1.77 g. $\mathrm{L}^{-1}$ of the bark powder to $\mathrm{HCl} 1.10^{-3}$ mol. $\mathrm{L}^{-1}$ solution, which is less aggressive than the other solution used in the present work, in order to avoid the evolution of hydrogen bubbles during the experiment. For this technique is mandatory to know the electrolyte resistivity value and in this study it was verified that the presence of corrosion inhibitor increases the bulk electrolyte resistivity value $(3370 \Omega . \mathrm{cm})$ due to the presence of organic compounds, when compared with the blank condition (2207 $\Omega . \mathrm{cm})$. Thus, localized ionic currents determined by local ratio of potential difference in the perpendicular direction to the surface and electrolyte resistivity became lower in the presence of the inhibitor (less $\mathrm{Fe}^{+2}$ ions are released from carbon steel surface) indicating the protective role of the castor bark powder.

The SVET ionic currents maps are show in Figure 6. The sample in the blank solution presents anodic and cathodic areas that represent the electrochemical activity and attack to the metal by the aggressive medium. After $90 \mathrm{~min}$ and 240 min of immersion, the current values were intensified due to the evolution of anodic and cathodic reactions, resulting in uniform corrosion of the surface.

The powder was added to the aggressive medium 15 minutes before the immersion of the metal in the solution and the beginning of ionic current measurements. The sample immersed in the electrolyte containing the castor bark powder, after only 2 min of immersion, shows that both anodic and cathodic currents were drastically reduced in comparison

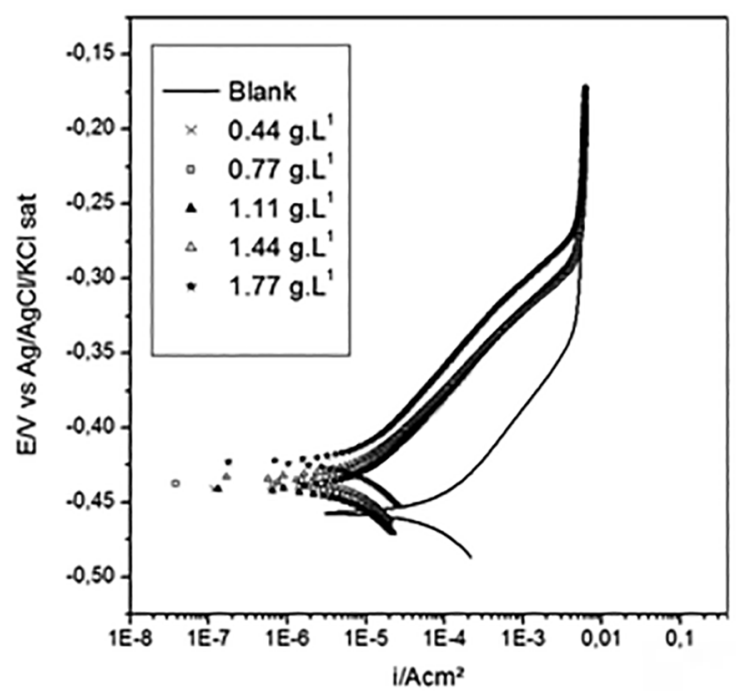

(a)

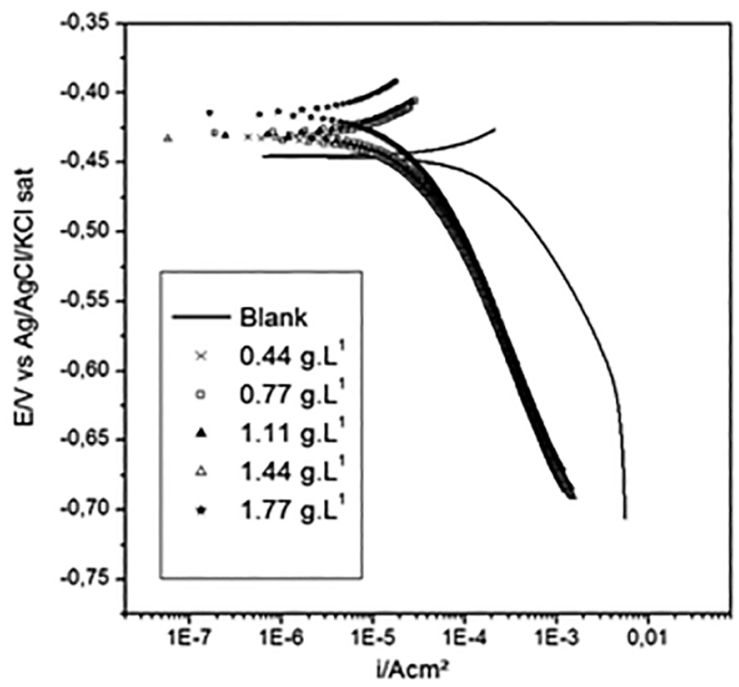

(b)

Figure 5. Potentiodynamic polarization curves for AISI 1020 carbon steel in 0.5 mol.L $\mathrm{L}^{-1} \mathrm{HCL}$ solution in the absence and presence of different amounts of castor bark powder: anodic (a) and cathodic (b) branches. 
a)

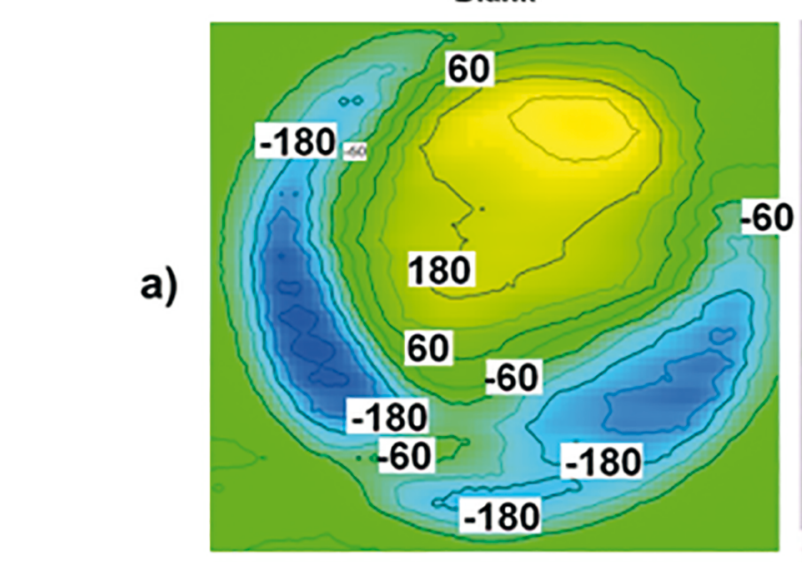

\section{Blank}

b)

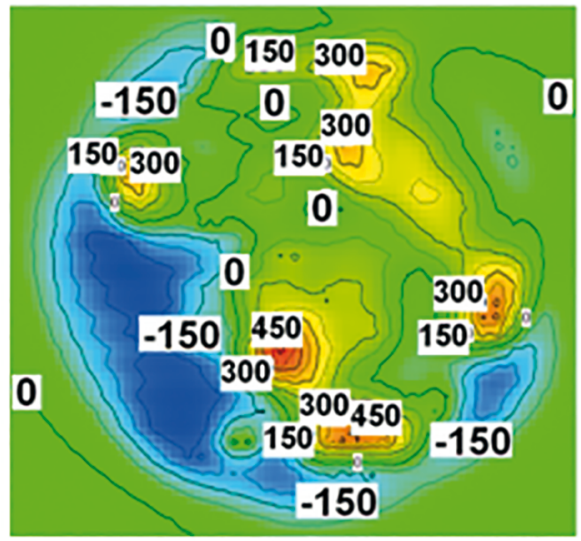

c)

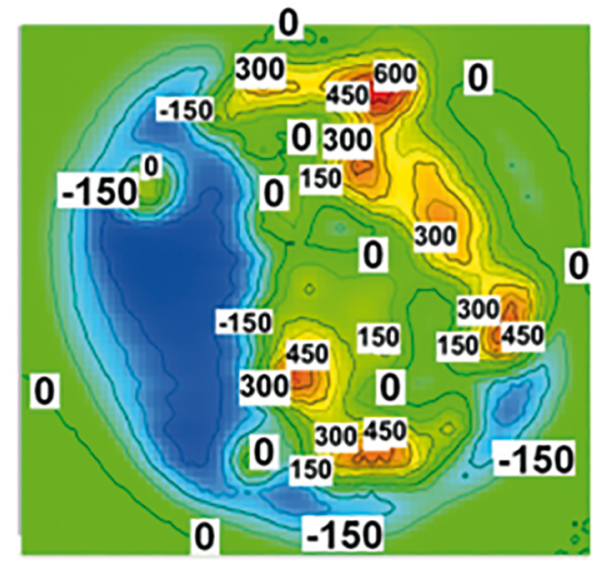

0
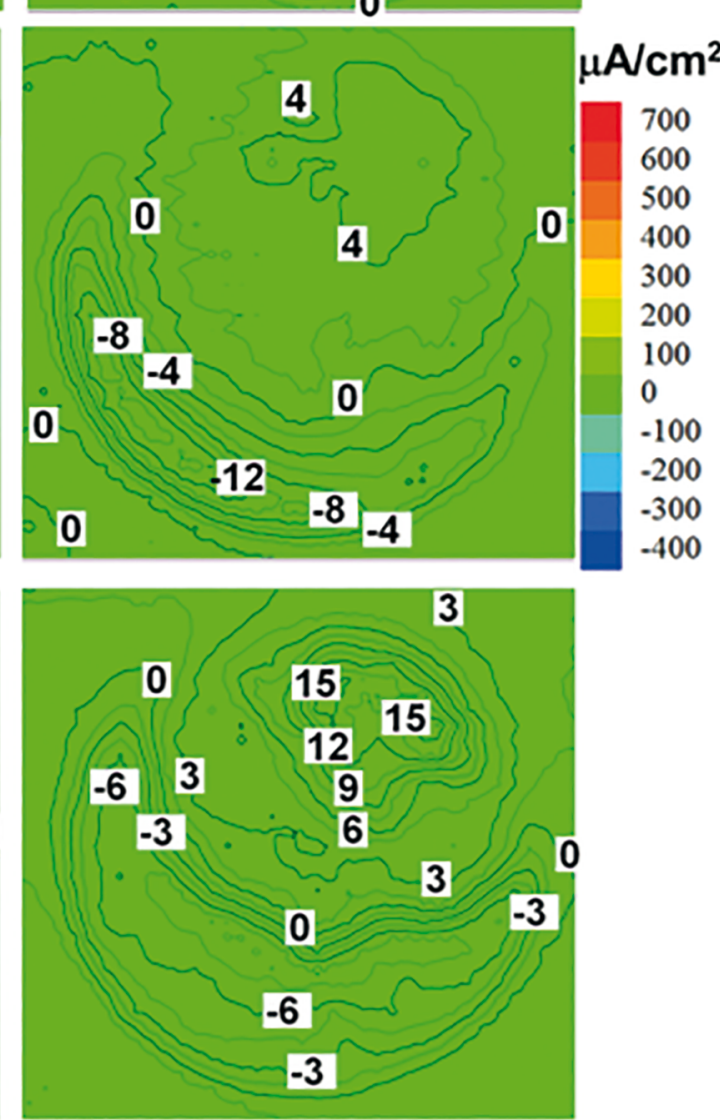

Samples aspect after 240 minutes of immersion
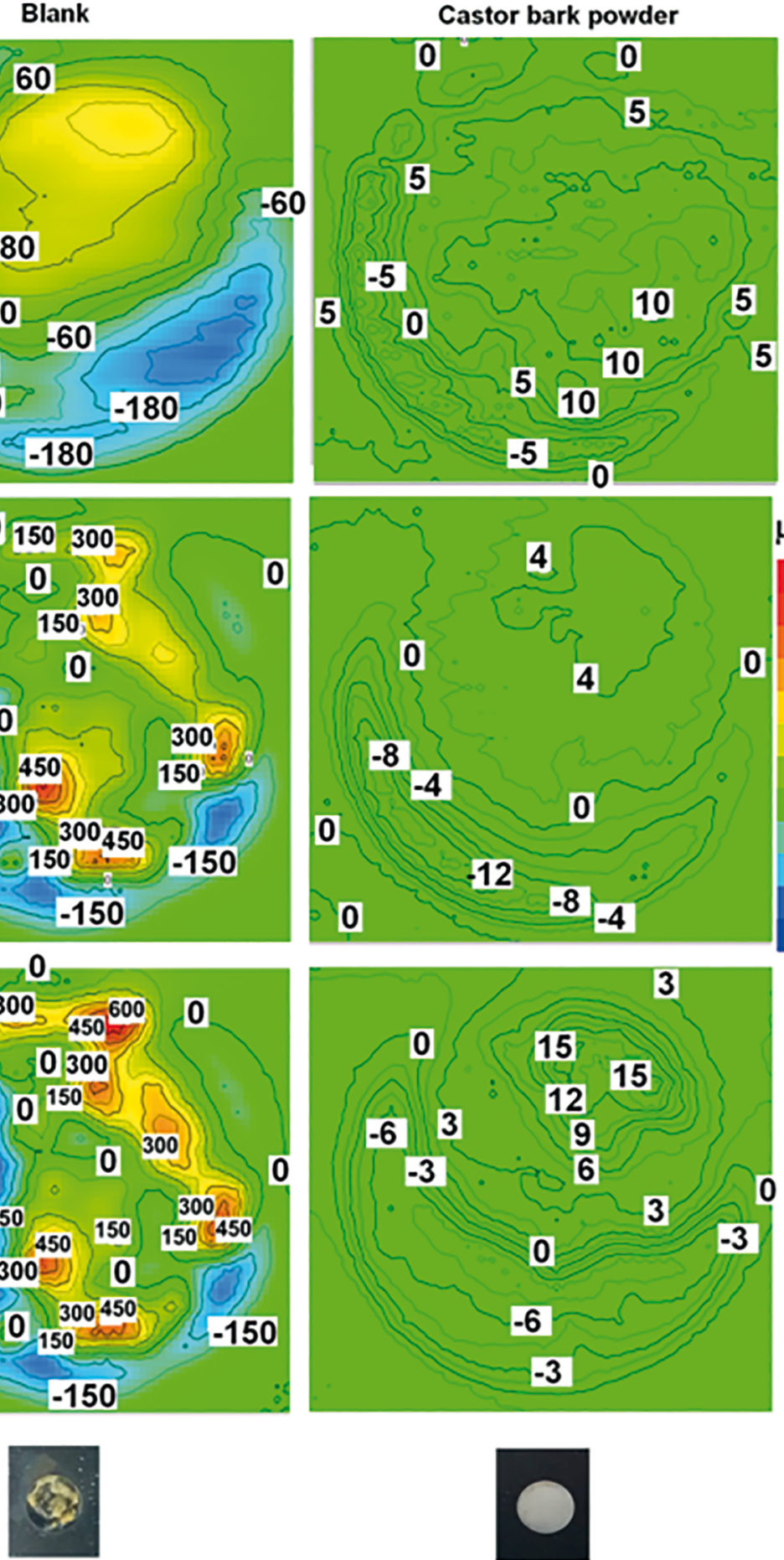

400

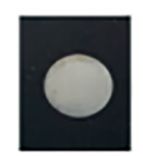

Figure 6. SVET ionic current maps for different immersion times for AISI 1020 carbon steel in absence and in the presence of castor bark powder in $1 \times 10^{-3}$ mol. $\mathrm{L}^{-1} \mathrm{HCl}$ and the visual aspect of the samples after a) $\left.2 \mathrm{~min}, \mathrm{~b}\right) 90 \mathrm{~min}$ and c) $240 \mathrm{~min}$ of immersion.

with the blank solution. After 90 and 240 min of test, it can be observed that the behaviour is maintained, the ionic current densities were lower than in the blank solution, proving the inhibitory action of the natural inhibitor leached from the castor bark powder. However, the cathodic current values were concentrated in one region of the sample, indicating that the adsorption process is not completely uniform. 
The visual aspect of the samples after $240 \mathrm{~min}$ of immersion (Figure 6) shows that there is no formation of corrosion products on the substrate surface in the presence of the powder, whereas a corroded surface was observed for the sample immersed in the blank solution, confirming, once more, the efficiency of the castor bark powder as corrosion inhibitor.

\section{Mechanism of Inhibition}

The analysis of EIS, SVET and gravimetric results showed a higher corrosion resistance for AISI 1020 carbon steel when the castor bark powder was added to the aggressive electrolyte. According to thermodynamic calculations, the corrosion inhibition mechanism can be ascribed to the adsorption on the metal surface of molecules leached from the castor bark powder, forming a protective barrier, thus reducing CS oxidation and the $\mathrm{H}^{+}$reduction reaction, as demonstrated by the polarization curves. The inhibitive action of castor bark could be explained by the presence of $\mathrm{O}, \mathrm{N}$, heteroatoms in the leached molecules that are usually found on corrosion inhibitors that act as adsorption centers ${ }^{13}$ and which functionalities were identified in the FTIR spectrum.

The literature suggests that the presence of chloride ions in acidic medium enables the existence of organic constituents of inhibitor in the protonated form as well as neutral molecules, and the adsorption of inhibitor molecules due to excess of negative charge on the metal surface, enhancing the electrostatic interactions between protonated inhibitor molecules and the negatively charged metal surface ${ }^{4,8}$. On the other hand, neutral molecules reduce the metal dissolution by its adsorption through lone pair of electrons over heteroatoms ${ }^{58}$.

The inhibiting molecules adsorbed at the metal surface block the active sites probably due to the displacement of water molecules through hydrogen bonding with hydroxyl groups of the inhibitor (Reaction 1). This results in the formation of a protective barrier that contributes to retard the ionic flow on the metal surface thus reducing the corrosion rate ${ }^{25,59,60}$.

$\mathrm{Org}_{\text {(sol) }}+x \mathrm{H}_{2} \mathrm{O}_{\text {(ads) }} \longrightarrow \mathrm{Org}_{\text {(ads) }}+x \mathrm{H}_{2} \mathrm{O}_{\text {(sol) }} \quad$ Reaction 1

where $x$ is the number of water molecules and $\operatorname{Org}$ is an organic inhibitor ${ }^{2}$.

\section{SEM Characterization}

SEM images of the AISI 1020 carbon steel surface were acquired before and after $2 \mathrm{~h}$ of immersion in $\mathrm{HCl} 0.5 \mathrm{~mol}^{\mathrm{L}} \mathrm{L}^{-1}$ in the absence and in the presence of $1.77 \mathrm{~g} \mathrm{~L}^{-1}$ of castor bark powder. Figure 7 depicts the image of a sample before immersion into aggressive medium. This Figure shows a surface free from corrosion products, but scratches due to the grinding procedure can be detected.

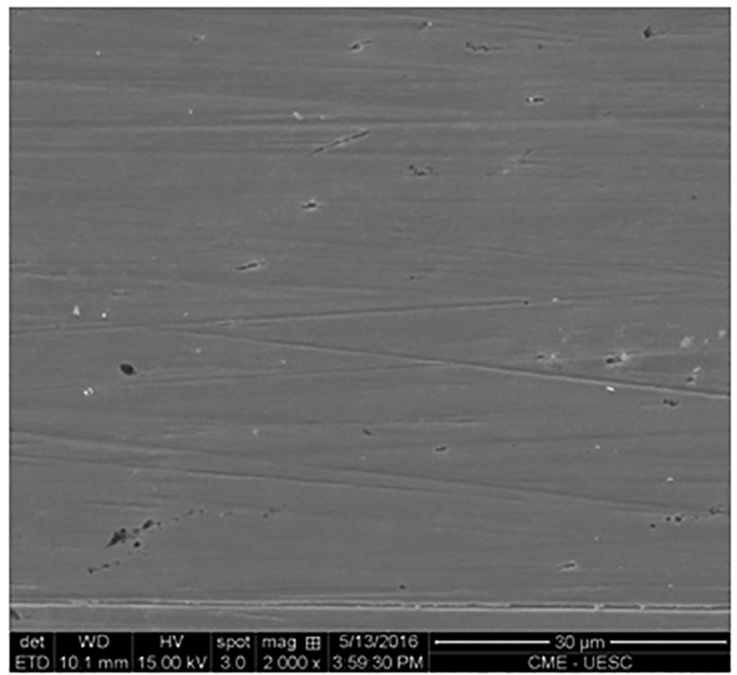

Figure 7. SEM micrograph of ground AISI 1020 carbon steel.

The substrate surface after $2 \mathrm{~h}$ immersion in the absence of inhibitor (Figure 8) revealed high degree of attack with the precipitation of corrosion products. On the other hand, when the castor bark powder was added to the solution (Figure 9) corrosion products were not clearly detected and scratch lines are still visible in the surface confirming that the metal is effectively protected from the corrosion process.

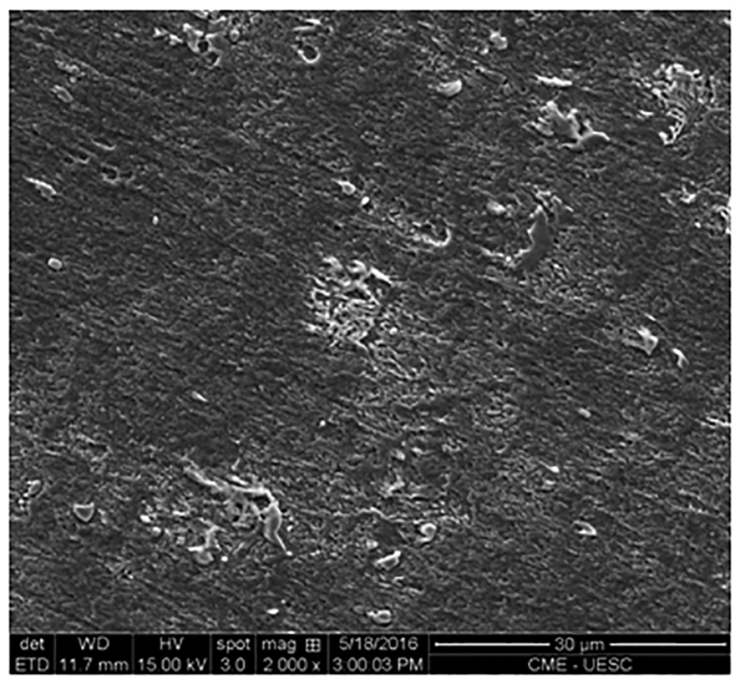

Figure 8. SEM micrograph of AISI 1020 carbon steel after $2 \mathrm{~h}$ immersion in $\mathrm{HCl} 0.5$ mol. $\mathrm{L}^{-1}$.

Figure 10 shows the substrate surface after $12 \mathrm{~h}$ of immersion in the absence of inhibitor. It can be seen a higher degree of attack in comparison with Figure 8 ( 2 hours of immersion). However, in the presence of castor bark powder (Figure 11), even with the high time of exposure, the substrate surface was less attacked than in absence of inhibitor, presenting few corrosion products, indicating the inhibitory property of the castor bark powder. 


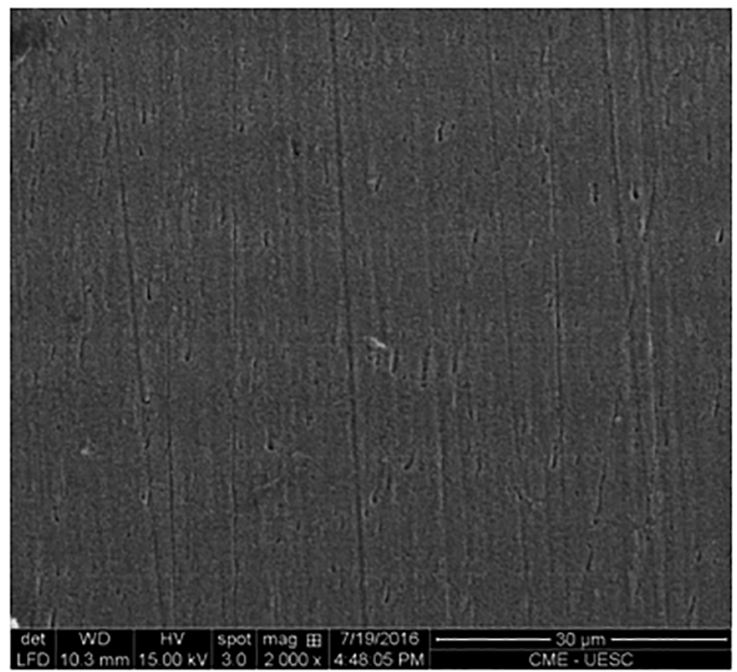

Figure 9. SEM micrograph of AISI 1020 carbon steel after $2 \mathrm{~h}$ of immersion in $\mathrm{HCl} 0.5$ mol. $\mathrm{L}^{-1}$ in the presence of $1.77 \mathrm{~g} . \mathrm{L}^{-1}$ of castor bark powder.

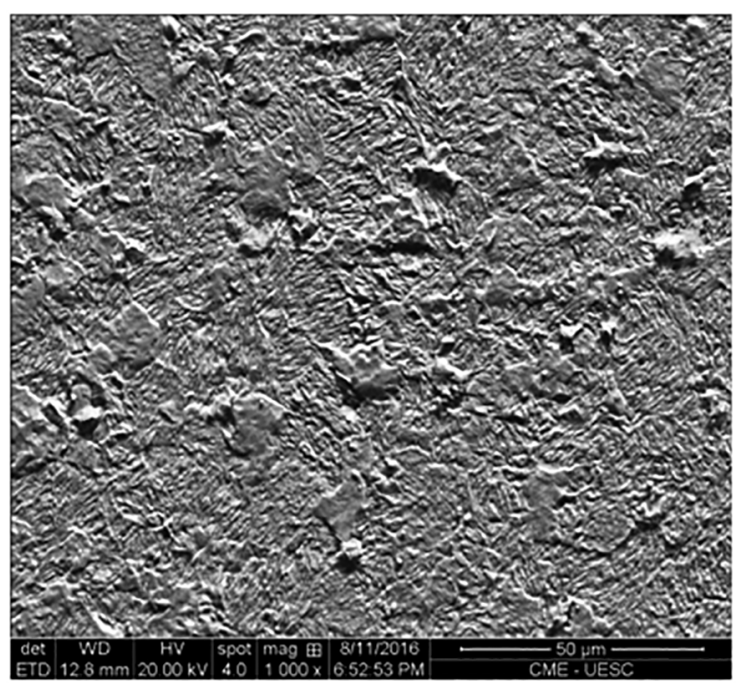

Figure 10. SEM micrograph of AISI 1020 carbon steel after $12 \mathrm{~h}$ immersion in $\mathrm{Cl} 0.5$ mol. $\mathrm{L}^{-1}$.

\section{Conclusions}

The results of the corrosion and, of the electrochemical tests showed that castor bark powder is a potential inhibitor against corrosion of 1020 carbon steel in $0.5 \mathrm{~mol} \mathrm{~L}^{-1} \mathrm{HCl}$ with the inhibiting efficiency increasing when higher amounts of the powder was added to the aggressive solution.

The results of the electrochemical tests (EIS and polarization curves) indicated that the corrosion mechanism was not changed when the powder was added to the solution, whereas the polarization curves showed a mixed inhibitor behaviour with slight anodic predominance. SVET measurements show that in the presence of inhibitors both anodic and cathodic

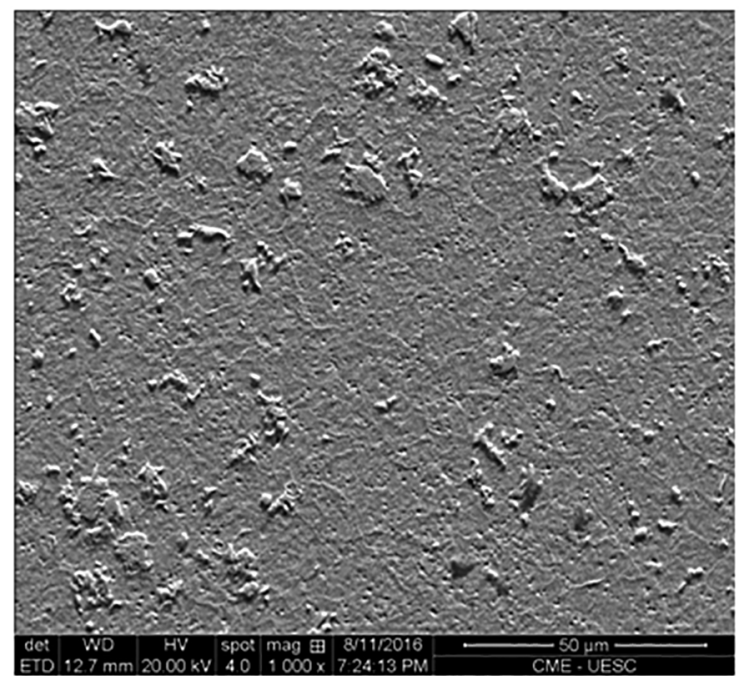

Figure 11. SEM micrograph of AISI 1020 carbon steel after $12 \mathrm{~h}$ of immersion in $\mathrm{HCl} 0.5$ mol.L $\mathrm{L}^{-1}$ in the presence of $1.77 \mathrm{~g} . \mathrm{L}^{-1}$ of castor bark powder.

ionic currents became significantly lower showing that the technique can be used to prove the inhibition of molecules on metal surface.

Thermodynamic considerations showed that the inhibiting molecules are weakly adsorbed to the metal surface (physisorption) according a Langmuir type adsorption isotherm, which probably takes place by interaction of heteroatoms with the metal surface, as indicated by the FTIR analysis.

Finally, an inhibitory efficiency of $83 \%$ was determined for the highest amount of castor bark powder added (1.77 g. $\left.\mathrm{L}^{-1}\right)$ to the $\mathrm{HCl} 0.5 \mathrm{~mol} \mathrm{~L}^{-1}$, which is compatible with results available for others green inhibitors ${ }^{10,29,31}$ as well as determined for other castor oil compound $\mathrm{s}^{20-22}$. However, in accordance with the adsorption isotherm calculations, the results showed a decrease of the inhibition efficiency with immersion time, indicating that the castor bark powder can be used only in applications where long immersion periods are not required.

\section{Acknowledgements}

Authors would like to acknowledge to FAPESB (Amparo Foudation for Research of the State of Bahia) for financial support, the BIOMA (Environment and Bioenergy Group) of State University of Santa Cruz (BA, BR) for FTIR analysis, LAMMA (Environment and Materials Laboratory) of State University of Santa Cruz (BA, BR) for support, LEC (Electrochemical and Corrosion Laboratory) of University of São Paulo (SP, BR) for SVET analysis and CME (Electronic Microscopy Center) of State University of Santa Cruz (BA, BR) for SEM images. 


\section{References}

1. Prabakaran M, Kim SH, Hemapriya V, Chung IM. Tragia plukenetii extract as an eco-friendly inhibitor for mild steel corrosion in $\mathrm{HCl} 1 \mathrm{M}$ acidic medium. Research on Chemical Intermediates. 2016;42(4):3703-3719. DOI: 10.1007/s11164$015-2240-\mathrm{x}$

2. Rocha JC, Gomes JACP, D'Elia E. Aqueous extracts of mango and orange peel as green inhibitors for carbon steel in hydrochloric acid solution. Materials Research. 2014;17(6):1581-1587. DOI: $10.1590 / 1516-1439.285014$

3. El-Etre AY. Inhibition of C-steel corrosion in acidic solution using the aqueous extract of zallouh root. Materials Chemistry and Physics. 2008;108(2-3):278-282.

4. Prabakaran M, Kim SH, Hemapriya V, Gopiraman M, Kim IS, Chung IM. Rhus verniciflua as a green corrosion inhibitor for mild steel in $1 \mathrm{M} \mathrm{H}_{2} \mathrm{SO}_{4}$. RSC Advances. 2016;6(62):5714457153.

5. Khan G, Newaz KMS, Basirun WJ, Ali HBM, Faraj FL, Khan GM. Application of Natural Product Extracts as Green Corrosion Inhibitors for Metals and Alloys in Acid Pickling Processes A review. International Journal of Electrochemical Science. 2015;10:6120-6134

6. Ji G, Dwivedi P, Sundaram S, Prakash R. Aqueous extract of Argemone mexicana roots for effective protection of mild steel in an $\mathrm{HCl}$ environment. Research on Chemical Intermediates. 2016;42(2):439-459. DOI: 10.1007/s11164-015-2029-y.

7. Boumhara K, Tabyaoui M, Jama C, Bentiss F. Artemisia Mesatlantica essential oil as green inhibitor for carbon steel corrosion in $1 \mathrm{M} \mathrm{HCl}$ solution: Electrochemical and XPS investigations. Journal of Industrial and Engineering Chemistry. 2015;29:146-155. DOI: 10.1016/j.jiec.2015.03.028

8. Nazeer AA, Shalabi K, Fouda AS. Corrosion inhibition of carbon steel by Roselle extract in hydrochloric acid solution: electrochemical and surface study. Research on Chemical Intermediates. 2015;41(7):4833-4850. DOI: 10.1007/s11164014-1570-4

9. Sobhi M, El-Noawany HH, El-Etre AY. Inhibition of Carbon Steel Corrosion in Acid Mediumin by Eruca sativa Extract. Journal of Basic and Environmental Sciences. 2015;2:9-18.

10. Benahmed M, Djeddi N, Akkal S, Laouar H. Saccocalyx satureioides as corrosion inhibitor for carbon steel in acid solution. International Journal of Industrial Chemistry. 2016;7(2):109-120. DOI: 10.1007/s40090-016-0082-z

11. Akalezi CO, Oguzie EE. Evaluation of anticorrosion properties of Chrysophyllum albidum leaves extract for mild steel protection in acidic media. International Journal of Industrial Chemistry. 2016;7(1):81-92. DOI: 10.1007/s40090-015-0057-5

12. Flores-de los Ríos JP, Sánchez-Carrillo M, Nava-Dino CG, Chacón-Nava JG, Escobedo-Bretado MA, Monreal-Romero HA, et al. Corrosion Inhibition of Mild Steel using Agavoideae extract in $1 \mathrm{M} \mathrm{HCl}$ solution. International Journal of Electrochemical Science. 2015;10:10210-10222.
13. Karthik R, Muthukrishnan P, Chen SM, Jeyaprabha B, Prakash P. Anti-Corrosion Inhibition of Mild Steel in $1 \mathrm{M}$ Hydrochloric Acid Solution by using Tiliacora accuminata leaves Extracts. International Journal of Electrochemical Science. 2015;10:37073725 .

14. Anupama KK, Ramya K, Shainy KM, Joseph A. Adsorption and electrochemical studies of Pimenta dioica leaf extracts as corrosion inhibitor for mild steel in hydrochloric acid. Materials Chemistry and Physics. 2015;167:28-41.

15. Souza TF, Magalhães M, Torres VV, D'Elia E. Inhibitory Action of Ilex paraguaensis Extracts on the Corrosion of Carbon Steel in $\mathrm{HCl}$ Solution. International Journal of Electrochemical Science. 2015;10:22-33.

16. Chevalier M, Roberta F, Amusantb N, Traisnelc M, Roosa C, Lebrina M. Enhanced corrosion resistance of mild steel in 1 M hydrochloric acid solution by alkaloids extract from Aniba rosaeodora plant: Electrochemical, phytochemical and XPS studies. Electrochimica Acta. 2014;131:96-105. DOI: 10.1016/j. electacta.2013.12.023

17. Khadraoui A, Khelifa A, Boutoumi H, Hamitouche H, Mehdaoui $\mathrm{R}$, Hammouti B, et al. Adsorption and Inhibitive Properties of Ruta chalepensis L. Oil as a Green Inhibitor of Steel in $1 \mathrm{M}$ Hydrochloric Acid Medium. International Journal of Electrochemical Science. 2014;9:3334-3348.

18. Souto KC, Sicsú AB. A cadeia produtiva da mamona no estado da Paraíba: uma análise pós-programa do biodiesel. REN Revista Econômica do Nordeste. 2011;42(1):183-210.

19. Li J, Gu D, Liu Y, Huang F, Yang Y. Large-scale separation of ricinine from a by-product of Ricinus communis L. By $\mathrm{pH}$-zone-refining counter-current chromatography. Industrial Crops and Products. 2013;49:160-163.

20. Sathiyanathan RAL, Maruthamuthu S, Selvanayagam M, Mohanan S, Palaniswamy N. Corrosion inhibition of mild steel by ethanolic extracts of Ricinus communis leaves. Indian Journal of Chemical Technology. 2005;12:356-360.

21. Goel R, Siddiqi WA, Ahmed B, Hussan J. Corrosion Inhibition of Mild Steel in $\mathrm{HCl}$ by Isolated Compounds of Riccinus communis (L.). E-Journal of Chemistry. 2010;7(Supp 1):S319-S329.

22. Vyas S, Soni S. Castor Oil as Corrosion Inhibitor for Iron in Hydrochloric acid. Oriental Journal of Chemisty. 2011;27(4):17431746.

23. Barreto LS. Desenvolvimento de inibidores de corrosão com resíduos vegetais para o aço carbono 1020. [Dissertation]. Ilhéus: State University of Santa Cruz; 2015.

24. ASTM International. ASTM G1-03 - Standard Practice for Preparing, Cleaning and Evaluating Corrosion Test Specimens. West Conshohocken: ASTM International; 2003.

25. Verma KD, Khan F. Corrosion inhibition of mild steel in hydrochloric acid using extract of glycine max leaves. Research on Chemical Intermediates. 2016;42(4):3489-3506. DOI: 10.1007/s11164-015-2227-7

26. Yetri Y, Emriadi, Jamarun N, Gunawarman. Corrosion Behavior of Environmental Friendly Inhibitor of Theobrama cacao Peels Extract for Mild Steel in $\mathrm{NaCl} 1.5$ M. EnvironmentAsia. 2016;9(1):45-59. 
27. Hijazi KM, Abdel-Garber AM, Younes GO. Electrochemical Corrosion Behavior of Mild Steel in $\mathrm{HCl}$ and $\mathrm{H}_{2} \mathrm{SO}_{4}$ Solutions in Presence of Loquat Leaf Extract. International Journal of Electrochemical Science. 2015;10:4366-4380.

28. Grassino AN, Hamlabek J, Djakovic S, Brncic SR, Dent M, Grabaric Z. Utilization of tomato peel waste from canning factory as a potential source for pectin production and application as tin corrosion inhibitor. Food Hydrocolloids. 2016;52:265-274. DOI: $10.1016 /$ j.foodhyd.2015.06.020

29. Li X, Deng S, Fu H. Inhibition of the corrosion of steel in $\mathrm{HCl}$, $\mathrm{H}_{2} \mathrm{SO}_{4}$ solutions by bamboo leaf extract. Corrosion Science. 2012;62:163-175.

30. Ikeuba AI, Okafor PC, Ekpe UJ, Ebenso EE. Alkaloid and Non-Alkaloid Ethanolic Extracts from Seeds of Garcinia kola as Green Corrosion Inhibitors of Mild Steel in $\mathrm{H}_{2} \mathrm{SO}_{4}$ Solution. International Journal of Electrochemical Science. 2013;8:7455-7467.

31. Muthukrishnan P, Prakash P, Ilayaraja M, Jeyaprabha B, Shankar K. Effect of Acidified Feronia elephantum Leaf Extract on the Corrosion Behavior of Mild Steel. Metallurgical and Materials Transactions B. 2015;46(3):1448-1460. DOI: 10.1007/s11663015-0322-1

32. Mourya P, Banerjee S, Singh MM. Corrosion inhibition of mild steel in acidic solution by Tagetes erecta (Marigold flower) extract as a green inhibitor. Corrosion Science. 2014;85:352363. DOI: $10.1016 /$ j.corsci.2014.04.036

33. Rocha JC, Gomes JACP, D'Elia E, Cruz APG, Cabral LMC, Torres AG, et al. Grape Pomace Extracts as Green Corrosion Inhibitors for Carbon Steel in Hydrochloric Acid Solutions. International Journal of Electrochemical Science. 2012;7:1194111956.

34. Uhlig HH. Corrosion and Corrosion Control. Hoboken: Wiley; 1971.

35. Dada AO, Olalekan AP, Olatunya AM, Dada O. Langmuir, Freundlich, Temkin and Dubinin-Radushkevich Isotherms Studies of Equilibrium Sorption of $\mathrm{Zn}^{2+}$ unto Phosphoric Acid Modified Rice Husk. IOSR Journal of Applied Chemistry. 2012;3(1):38-45.

36. Hall KR, Eagleton LC, Acrivos A, Vermeulen T. Pore and SolidDiffusion Kinetics in Fixed-Bed Adsorption under ConstantPatterns Conditions. Industrial \& Engineering Chemistry Fundamentals. 1966;5(2):212-223.

37. Ghazouani T, Hmamou DB, Meddeb E, Salghi R, Benali O, Bouya $\mathrm{H}$, et al. Antioxidant activity and effect of quince pulp extract on the corrosion of C-Steel in $1 \mathrm{M} \mathrm{HCl}$. Research on Chemical Intermediates. 2015;41(10):7463-7480. DOI: 10.1007/ s11164-014-1837-9

38. Behpour M, Ghoreishi SM, Khayatkashani M, Soltani N. Green approach to corrosion inhibition of mild steel in two acidic solution by the extract of Punica granatum peel and main constituents. Materials Chemistry and Physics. 2012;131(3):621-633.

39. Torres VV, Amado RS, de Sá CF, Fernandez TL, Riehl CAS, Torres AG, et al. Inhibitory action of aqueous coffee ground extracts on the corrosion of carbon steel in $\mathrm{HCl}$ solution. Corrosion Science. 2011;53(7):2385-2392.
40. Pereira SSAA, Pêgas MM. Fernández TL, Magalhães M, Schöntag TG, Lago DC, et al. Inhibitory action of aqueous garlic peel extract on the corrosion of carbon steel in $\mathrm{HCl}$ solution. Corrosion Science. 2012;65:360-366.

41. Abiola OK, James AO. The effects of Aloe vera extract on corrosion and kinetics of corrosion process of zinc in $\mathrm{HCl}$ solution. Corrosion Science. 2010;52(2):661-664.

42. Banerjee S, Srivastava V, Singh MM. Chemically modified natural polysaccharide as green corrosion inhibitor for mild steel in acidic medium. Corrosion Science. 2012;59:35-41.

43. Khaled KF. New Synthesized Guanidine Derivative as a Green Corrosion Inhibitor for Mild Steel in Acidic Solutions. International Journal of Electrochemical Science. 2008;3:462475.

44. Ghailane T, Balkhmima RA, Ghailane R, Souizi A, Touir R, Ebn Touhami M, et al. Experimental and theoretical studies for mild steel corrosion inhibition in $1 \mathrm{M} \mathrm{HCl}$ by two new benzothiazine derivatives. Corrosion Science. 2013;76:317-324.

45. Zoltowski P. On the electrical capacitance of interfaces exhibiting constant phase element behaviour. Journal of Electroanalytical Chemistry. 1998;443(1):149-154.

46. Deslouis C, Tribollet B, Mengoli G, Musiani MM. Electrochemica behaviour of cooper in neutral aerated chlorid solution. II. Impedance investigation. Journal of Applied Electrochemistry. 1988;18(3):384-393.

47. Hernández RPB, Aoki IV, Tribollet B, de Melo HG. Electrochemica impedance spectroscopy investigation of the electrochemical behaviour of copper coated with artificial patina layers and submitted to wet and dry cycles. Electrochimica Acta. 2011;56(7):2801-2814.

48. de Levie R. On porous electrodes in electrolyte solutions: I. Capacitance effects. Electrochimica Acta. 1963;8(10):751-780.

49. de Levie R. On porous electrodes in electrolyte solutions-IV. Electrochimica Acta. 1964;9(9):1231-1245.

50. Cai M, Park SM. Oxidation of Zinc in Alkaline Solutions Studied by Electrochemical Impedance Spectroscopy. Journal of the Electrochemical Society. 1996;143(12):3895-3902.

51. de Levie R. On impedance measurements: The determination of the double layer capacitance in the presence of an electrode reaction. Electrochimica Acta. 1965;10(4):395-402.

52. Jorcin JB, Orazem ME, Pébère N, Tribollet B. CPE analysis by local electrochemical impedance spectroscopy. Electrochimica Acta. 2006;51(8-9):1473-1479

53. Orazem ME, Pébère N, Tribollet B. Enhanced Graphical Representation of Electrochemical Impedance Data. Journal of the Electrochemical Society. 2006;153(4):B129-B136.

54. Brug GJ, van den Eeden ALG, Sluyters-Rehbach M, Sluyters $\mathrm{JH}$. The analysis of electrode impedances complicated by the presence of a constant phase element. Journal of Electroanalytical Chemistry and Interfacial Electrochemistry. 1984;176(1-2):275295.

55. Espinoza-Vázquez A, Negrón-Silva GE, González-Olvera R, Angeles-Beltrán D, Herrera-Hernández H, Romero-Romo M, et al. Mild steel corrosion inhibition in $\mathrm{HCl}$ by di-alkyl and 
di-1,2,3-triazole derivatives of uracil and thymine. Materials Chemistry and Physics. 2014;145(3):407-417.

56. Moretti G, Guidi F, Fabris F. Corrosion inhibition of the mild steel in $0.5 \mathrm{M} \mathrm{HCl}$ by 2-butyl-hexahydropyrrolo[1,2-b][1,2] oxazole. Corrosion Science. 2013;76:206-218.

57. Mobin M, Rizvi M. Inhibitory effect of xanthan gum and synergistic surfactant additives for mild steel corrosion in 1M HCl. Carbohydrate Polymers. 2016;136:384-393. DOI: 10.1016/j.carbpol.2015.09.027
58. Shukla SK, Quraishi MA. Ceftriaxone: a novel corrosion inhibitor for mild steel in hydrochloric acid. Journal of Applied Electrochemistry. 2009;39(9):1517-1523.

59. Loto CA, Loto RT, Popoola API. Inhibition Effect of Extracts of Carica papaya and Camellia sinensis Leaves on the Corrosion of Duplex (A, B) Brass In 1M Nitric acid. International Journal of Electrochemical Science. 2011;6:4900-4914.

60. Negm NA, Yousef MA, Tawfik SM. Impact of Synthesized and Natural Compounds in Corrosion Inhibition of Carbon Steel and Aluminium in Acidic Media. Recent Patents on Corrosion Science. 2013;3. 


\section{Erratum}

In the article "Evaluation of Castor Bark Powder as a Corrosion Inhibitor for Carbon Steel in Acidic Media", DOI number: http://dx.doi.org/10.1590/1980-5373-mr-2016-0963, published in Mat. Res. in Oct 30, 2017, in the first page where it read:

André de Mendonça Santos ${ }^{\mathrm{a} *}$

Thassia Felix de Almeida ${ }^{a}$

Fernnado Cotting ${ }^{\mathrm{b}}$

Idalina Vieira Aoki ${ }^{b}$

Hercílio Gomes de Melo $^{\mathrm{c}}$

Vera Rosa Capelossi ${ }^{\mathrm{a}}$

It should be written:

André de Mendonça Santos ${ }^{\mathrm{a} *}$

Thassia Felix de Almeida ${ }^{a}$

Fernando Cotting ${ }^{\mathrm{b}}$

Idalina Vieira Aoki ${ }^{b}$

Hercílio Gomes de Melo ${ }^{c}$

Vera Rosa Capelossi ${ }^{\mathrm{a}}$ 